\title{
In vitro bioactivity studies of larnite and larnite/chitin composites prepared from biowaste for biomedical applications
}

\author{
RAJAN CHOUDHARY, SENTHIL KUMAR VENKATRAMAN, ANJALI RANA and \\ SASIKUMAR SWAMIAPPAN* \\ Department of Chemistry, School of Advanced Sciences, VIT University, Vellore 632014, India
}

MS received 30 December 2015; accepted 24 February 2016

\begin{abstract}
Larnite $\left(\mathrm{Ca}_{2} \mathrm{SiO}_{4}\right)$ was synthesized by the sol-gel combustion process by using raw eggshell powder as a calcium source and urea as a fuel. The main focus of this work is to convert biowaste into a biomedical material at a low-processing temperature. X-ray diffraction (XRD) pattern confirms the phase purity of the larnite and Fourier transform infrared (FTIR) spectra confirms the presence of characteristic functional groups of larnite. Scanning electron microscopy (SEM) image shows agglomerated particles with cauliflower-like morphology and energy dispersive X-ray spectroscopy (EDX) confirms the presence of the stoichiometric ratio of required elements. Atomic force microscope (AFM) images reveal the presence of pores on the surface of spherical particles. Larnite/chitin composites were fabricated into scaffold with different ratios of bioceramic to biopolymer $(70: 30,80: 20)$ to investigate the influence of the polymer content on the apatite formation ability in simulated body fluid (SBF) medium. XRD pattern and FTIR spectra of the scaffold immersed in SBF shows apatite deposition within 5 days. The deposition of hydroxyapatite (HAP) on the scaffold surface increases with the increase in polymer content of the composite.
\end{abstract}

Keywords. Dicalcium silicate; sol-gel processes; chitin; composites; SEM; apatite.

\section{Introduction}

Wide range of silicate biomaterials possess high demand in hard tissue engineering ranging from bone implants to repairing of damaged or worn out hard tissues. Dentistry has been advanced with bioceramics as dental fillers or implants which matches to the patient's natural teeth in terms of appearance as well as functions [1]. Thus, a lot of attention is paid towards the use of bioactive fixation of implant to tissue by means of hydroxyapatite (HAP) deposition on the implant surface [2]. Calcium phosphate bioceramics such as HAP, tricalcium phosphate and their composites have been widely explored, but due to inferior mechanical properties, their applications are now seems to be limited to non-load bearing implants [3]. In 1971, Hench [4] discovered that 'bioactive glasses can tightly bind to living bone'. This led to the rapid growth in the field of silicate bioglass to find out their biocompatibility and bioactivity responses in a physiological environment. Moreover, recent investigations are focussed on the development of silicate bioactive glasses for hard tissue engineering as they actively participate in physiological reactions at implant site to form tight bonding with host bone tissues [5]. Superior mechanical strength comparing to calcium phosphate biomaterials made silicates as a primary choice among biomaterials.

Bioactivity studies carried out on silicate bioceramics such as wollastonite, akermanite, diopside, bregidite, etc., show very good bioactivity and biocompatibility [6-8]. Amongst these

*Author for correspondence (ssasikumar@vit.ac.in) calcium silicate bioceramics, wollastonite has been widely investigated due to its high biocompatibility when compared with other silicate bioceramics. When compared to wollastonite, synthesis and bioactivity studies on larnite [9-12] and its composites are not much explored [13-15]. The molar concentration of calcium in larnite structure is twice to that of wollastonite as a result, it is found to possess improved bioactivity than wollastonite $[9,10]$. The high brittleness of bioceramics limits their applications for load and stress bearing implants. This disadvantage can be overcome by fabricating the composites of bioceramics with polymers [16]. Thus, the high significance is given towards the preparation of bioceramic composites with natural or synthetic polymers. The major problem is the appropriate selection of polymer which should be biodegradable, should possess $\mathrm{pH}$ stability, cell adhesion with biological signalling, etc. $[17,18]$. These unique characteristics are shown by natural polymers and considered as potential scaffold preparing materials for biomedical applications.

New preparatory routes are developed to utilize the biogenic waste sources for the preparation of bioceramics through green synthesis as it is cost-effective and environmentalfriendly. Amongst various biowastes, eggshell waste is found to be very high as 250,000 tons of waste produced across the globe. These discarded eggshells require at least six years for decomposing and in this duration, there will be a microbial growth on its surface with foul smell contributing to environmental pollution. Eggshell comprises of approximately $95 \%$ calcium carbonate, remaining are protein and organic matter 
[19]. Extraction of calcium from eggshell is easier and cheaper as compared to utilization of seashells such as oyster shells, corbicula shell or animal bones for calcium extraction [2022]. Thus, a large number of investigations are conducted towards the use of eggshells as calcium source for the production of valuable bioceramics.

In this study, we have attempted to prepare eggshellderived larnite at low temperature by employing sol-gel combustion route. Further, pure larnite and its composites were prepared with natural polymer (chitin) by varying the compositions (80:20 and $70: 30$ ratios) to study the effect of polymer content on the bioactivity of the composites in simulated body fluid (SBF).

\section{Materials and methods}

\subsection{Materials}

Chicken eggshells, magnesium chloride analytical reagent (AR) $(99.0 \%$, SDFCL), pure urea $(99.0 \%$, Himedia), concentrated hydrochloric acid LR (35-38\%, SDFCL), concentrated nitric acid LR (69-72\%, SDFCL), sodium bicarbonate AR (99\%, Nice Chemicals), chitin (Himedia), tetraethyl ortho silicate (TEOS) (98\%, Acros Organics), calcium chloride AR (98\%, Qualigen Fine Chemicals), Eriochrome Black-T AR (99\%, SDFCL), ammonium chloride GR (98.8\%, MERCK), sodium chloride AR (99.9\%, SDFCL), ethylene diamine tetra acetic acid LR (98.0\%, SDFCL), dipotassium hydrogen orthophosphate AR (99.0\%, SDFCL), tris(hydroxymethyl)aminomethane AR (99.8\%, SDFCL), potassium chloride AR (99.5\%, SDFCL), ammonia solution extrapure AR (25\%, SRL) and sodium sulphate anhydrous AR $(99.5 \%$, SDFCL) were used in this study.

\subsection{Extraction of calcium from eggshell and estimation of calcium ions}

The present work is a continuation of our recently published work. Thus, the detailed procedure employed for the preparation of calcium nitrate using eggshell and estimation of ionic concentration of calcium in solution can be assessed as per earlier reported paper [15].

\subsection{Preparation of larnite by sol-gel combustion method}

The stoichiometric ratios of eggshell derived aqueous calcium nitrate $(2 \mathrm{M})$ and urea solution $(2 \mathrm{M})$ were taken and mixed thoroughly. Later, TEOS (1 M) was added to the mixture with constant stirring for $10 \mathrm{~min}$ at room temperature. The $\mathrm{pH}$ of the solution was adjusted to 1 by the addition of concentrated nitric acid. The resultant solution was stirred constantly for $28 \mathrm{~h}$ in a covered beaker. The thick gel formed was dried at $200^{\circ} \mathrm{C}$ for $3 \mathrm{~h}$ and the decomposition of dried powder was carried out at $400^{\circ} \mathrm{C}$ for $1 \mathrm{~h}$ in the preheated muffle furnace. The precursor was grounded into a fine powder and calcined at $800^{\circ} \mathrm{C}$ for $6 \mathrm{~h}$. The calcined product was later characterized by powder X-ray diffraction (XRD), Fourier transform infrared (FTIR), atomic force microscope (AFM), scanning electron microscopy (SEM) and energy dispersive $\mathrm{X}$-ray spectroscopy (EDX).

\subsection{Preparation of larnite/chitin composite and in vitro bioactivity studies}

To study the bioactivity of larnite and its composites in SBF, three scaffolds were prepared by using pure larnite and larnite/chitin composites of ratios $80: 20$ and $70: 30$. Scaffolds were fabricated manually by thorough mixing of larnite with chitin in mortar and pestle, and the resultant mixture was pelletized into $13 \mathrm{~mm}$ diameter pellets by applying a pressure of about $20 \mathrm{MPa}$ as mentioned in earlier studies [15]. The SBF solution was prepared according to previous reports [23]. These fabricated scaffolds were separately soaked in $50 \mathrm{ml} \mathrm{SBF}$ with the $\mathrm{pH}$ of 7.4 and incubated at $37^{\circ} \mathrm{C}$ for 5 days. The SBF was replaced after every $24 \mathrm{~h}$ to facilitate the nucleation of HAP on the scaffold surface by continuous delivery of calcium and phosphate ions from the SBF upto 5th day. The scaffolds were taken out from the SBF, washed with deionized water and dried at $60^{\circ} \mathrm{C}$. Finally, the dried surface of all three samples was examined by powder-XRD, FTIR and SEM/EDAX (energy dispersive analysis of X-rays) to study the changes occurred in the surface after deposition of HAP layer.

\section{Characterization}

The phase purity of the synthesized larnite was studied by X-ray diffractometer (Bruker, D8 advance, Germany) by using $\mathrm{CuK} \alpha$, Ni-filtered radiation. Functional groups were examined by FTIR (IR Affinity-1, Shimadzu FTIR spectrophotometer). SEM (SEM-Carl Zeiss) was used for morphological characterization and EDX (EDX-Oxford Inc.) for the elemental analysis. Surface topography and morphology were analysed by AFM (Nano Surf Easy 2 Scan Controller).

\section{Results and discussion}

\subsection{FTIR analysis}

FTIR spectrum (figure 1a) of the precursor shows broad absorption bands corresponding to $\mathrm{OH}\left(3454 \mathrm{~cm}^{-1}\right), \mathrm{CO}_{3}^{2-}$ $\left(1421 \mathrm{~cm}^{-1}\right)$ and $\mathrm{Si}-\mathrm{O}-\mathrm{Si}\left(1000\right.$ and $\left.516 \mathrm{~cm}^{-1}\right)$ vibrations. The singlet peak at $873 \mathrm{~cm}^{-1}$ indicates symmetric stretching of $\mathrm{Si}-\mathrm{O}$ ion and the peak linkage at $710 \mathrm{~cm}^{-1}$ confirms the presence of $\mathrm{O}-\mathrm{Si}-\mathrm{O}$ group. These results indicate that phase formation of larnite was initiated during the combustion reaction. When the precursor was calcined at $800^{\circ} \mathrm{C}$ for $6 \mathrm{~h}$, the broad bands observed in precursor got transformed into sharp, intense peaks to produce a clear spectrum of functional groups present in larnite as shown in figure $1 \mathrm{~b}$. The bands at 518 and $995 \mathrm{~cm}^{-1}$ are assigned to $\mathrm{Si}-\mathrm{O}-\mathrm{Si}$ bending vibration modes and $\mathrm{Si}-\mathrm{O}-\mathrm{Si}$ asymmetric stretching vibrations. 
The band at $713 \mathrm{~cm}^{-1}$ corresponds to $\mathrm{O}-\mathrm{Si}-\mathrm{O}$ stretching modes. The bands in the range of $848-893 \mathrm{~cm}^{-1}$ indicate symmetric stretching modes of $\mathrm{Si}-\mathrm{O}$ bond. The stretching

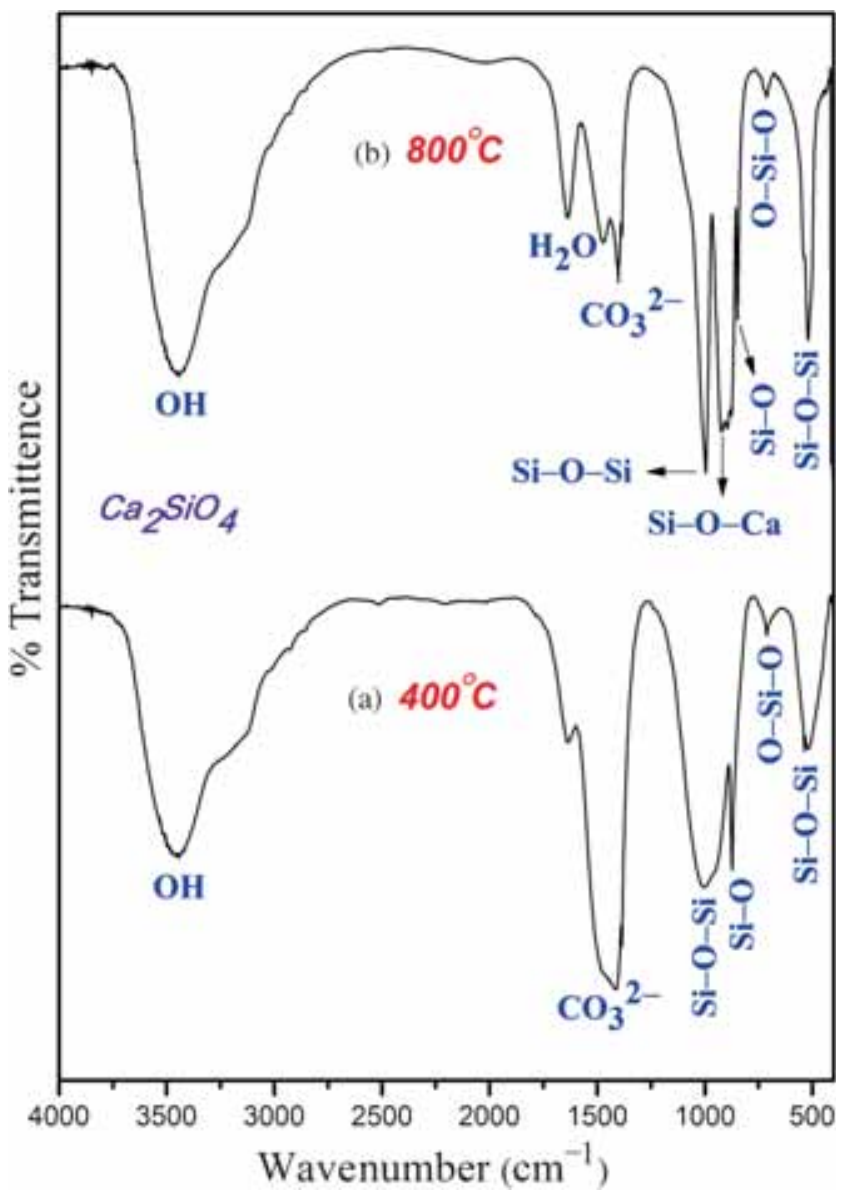

Figure 1. FTIR spectrum of: (a) precursor obtained from the combustion and (b) precursor calcined at $800^{\circ} \mathrm{C}$. vibration of non-bridging oxygen $\mathrm{Si}-\mathrm{O}-\mathrm{Ca}$ was observed at $921 \mathrm{~cm}^{-1}$. A band at $1400 \mathrm{~cm}^{-1}$ is due to the existence of carbonate group [24]. The band at $1631 \mathrm{~cm}^{-1}$ is due to moisture absorption and the band at $3441 \mathrm{~cm}^{-1}$ is due to $\mathrm{OH}$ bending vibration $[15,25]$.

\subsection{Phase analysis of synthesized larnite}

Powder XRD study was used to analyse the transformation of the precursor into single phase larnite prepared from raw eggshell. The precursor was calcined at various temperatures to obtain pure larnite phase. The XRD pattern (figure 2a) of precursor calcined at $500^{\circ} \mathrm{C}$ shows the presence of dual phases which is slightly amorphous in nature with larnite as a major phase. Among these obtained phases, the presence of calcite was confirmed by JCPDS data card no. 900-0969. When the calcination temperature was increased from 500 to $700^{\circ} \mathrm{C}$, larnite peaks cover major portion of the surface with gradual increase in their intensity (figure $2 b$ ). Moreover, hatrurite as a secondary phase was also noticed. This observation reveals that the phase formation of larnite was initiated at $500^{\circ} \mathrm{C}$ itself. As the temperature further increased to $800^{\circ} \mathrm{C}$ (figure 2c), the hatrurite phase was completely removed and the sharp and well-defined peaks corresponding to single phase larnite was observed. XRD pattern (figure 2d) of larnite was matched with a standard JCPDS data card no. 90-2792. The crystal system of the synthesized larnite is found to be monoclinic and lattice parameters calculated were found to be $a=5.50010 \AA, b=6.73726 \AA, c=9.30180 \AA$, $\beta=$ $94.625^{\circ}$. The crystallite size $(D)$ of larnite was calculated from the high intensity peaks by using the Debye-Scherer equation [26] and the calculated crystallite size was in the range of $20-30 \mathrm{~nm}$.

Earlier reports on larnite preparation reveal that pure phase of larnite is prepared at high temperature in the range of
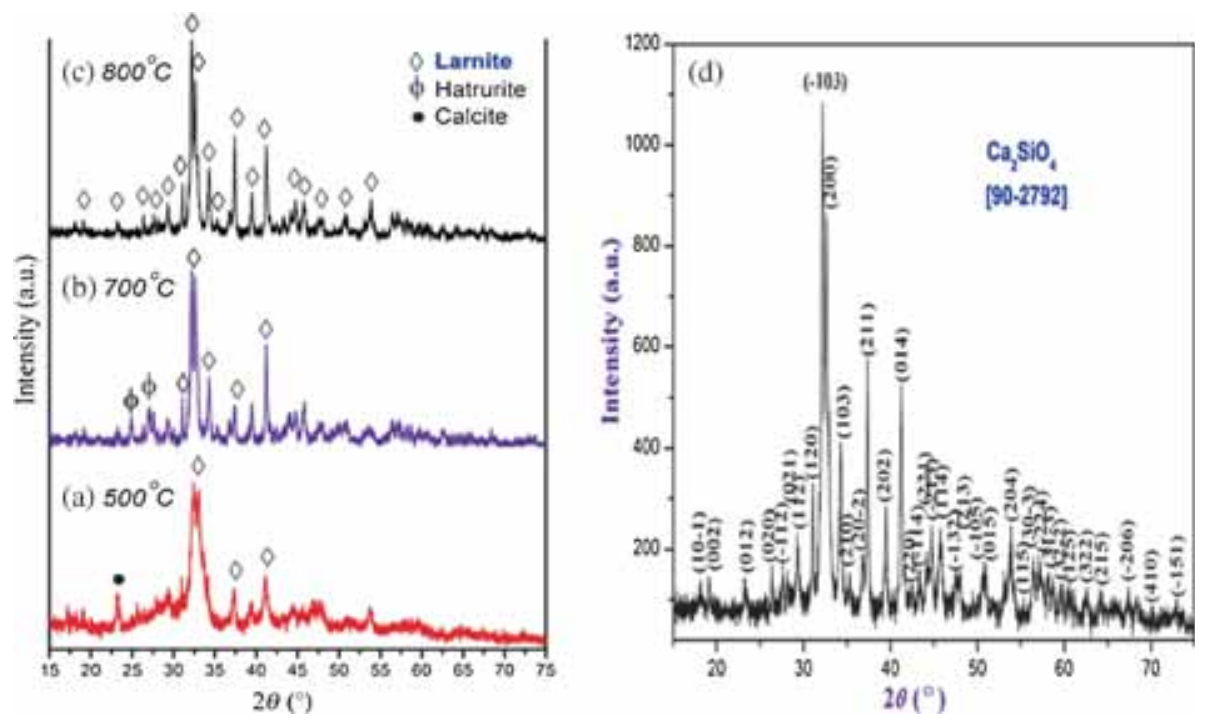

Figure 2. XRD pattern of larnite calcined at different temperatures: (a) $500^{\circ} \mathrm{C}$, (b) $700^{\circ} \mathrm{C}$, (c) $800^{\circ} \mathrm{C}$ and (d) indexed XRD pattern of pure larnite. 
$1000-1450^{\circ} \mathrm{C}[9,11]$. Recently, larnite was synthesized at $900^{\circ} \mathrm{C}$ by using citric acid as a fuel [15], whereas pure larnite phase is observed at $800^{\circ} \mathrm{C}$ in the current study by using urea as a fuel. This change in calcination temperature of larnite might be due to the variation in thermochemistry of the fuel used. The selection of an appropriate fuel plays a crucial role in phase formation of bioceramics. It has been found that rate of combustion of a fuel increases in the order of glycine $>$ urea $>$ citric acid [27]. Hence, sol-gel combustion method and rapid combustion rate of urea enable the preparation of single phase larnite at low temperature.

\subsection{SEM/EDX analysis}

SEM images (figure 3a) of larnite calcined at $800^{\circ} \mathrm{C}$ show cluster of irregular spherical crystallites agglomerated to form particles. The surface of larnite is found to have hairy fur that gives an appearance of cauliflower like morphology. Higher magnification of SEM image (figure $3 b$ ) shows the particle size is at nanoregime and particles are porous in nature with pore sizes in micrometer scale. The occurrence of these pores is due to evolution of nitrate, water vapour and ammonia during thermal decomposition. Elemental analysis of the calcined larnite was examined by EDX (figure 3c), which reveals the presence of calcium, silicon and oxygen atoms as the major constituent in the sample, which are in the agreement with the molecular formula of pure larnite $\left(\mathrm{Ca}_{2} \mathrm{SiO}_{4}\right)$. Thus, this finding reveals that pure phase of larnite can be prepared from raw eggshells by using sol-gel combustion method.

\section{$4.4 \quad A F M$}

AFM was used to characterize the topological parameters of the synthesized bioceramic [28]. The surface characteristics such as surface roughness and morphology of the implants help in regulation of cell proliferation, cell attachment and protein adsorption [29]. AFM images of larnite calcined at $800^{\circ} \mathrm{C}$ (figure 4 ) show porous surface and agglomerated particles having a spherical geometry. These images were found to be in agreement with the results obtained from SEM analysis (figure 3 ). It is reported that the high porosity helps in the ion exchange process between the bioceramic and SBF causing rapid apatite formation $[30,31]$.

\section{In vitro bioactivity analysis of larnite and larnite/ chitin composites}

The basic criteria for an implant material is to repair or replace damaged and fractured bone by creating a direct
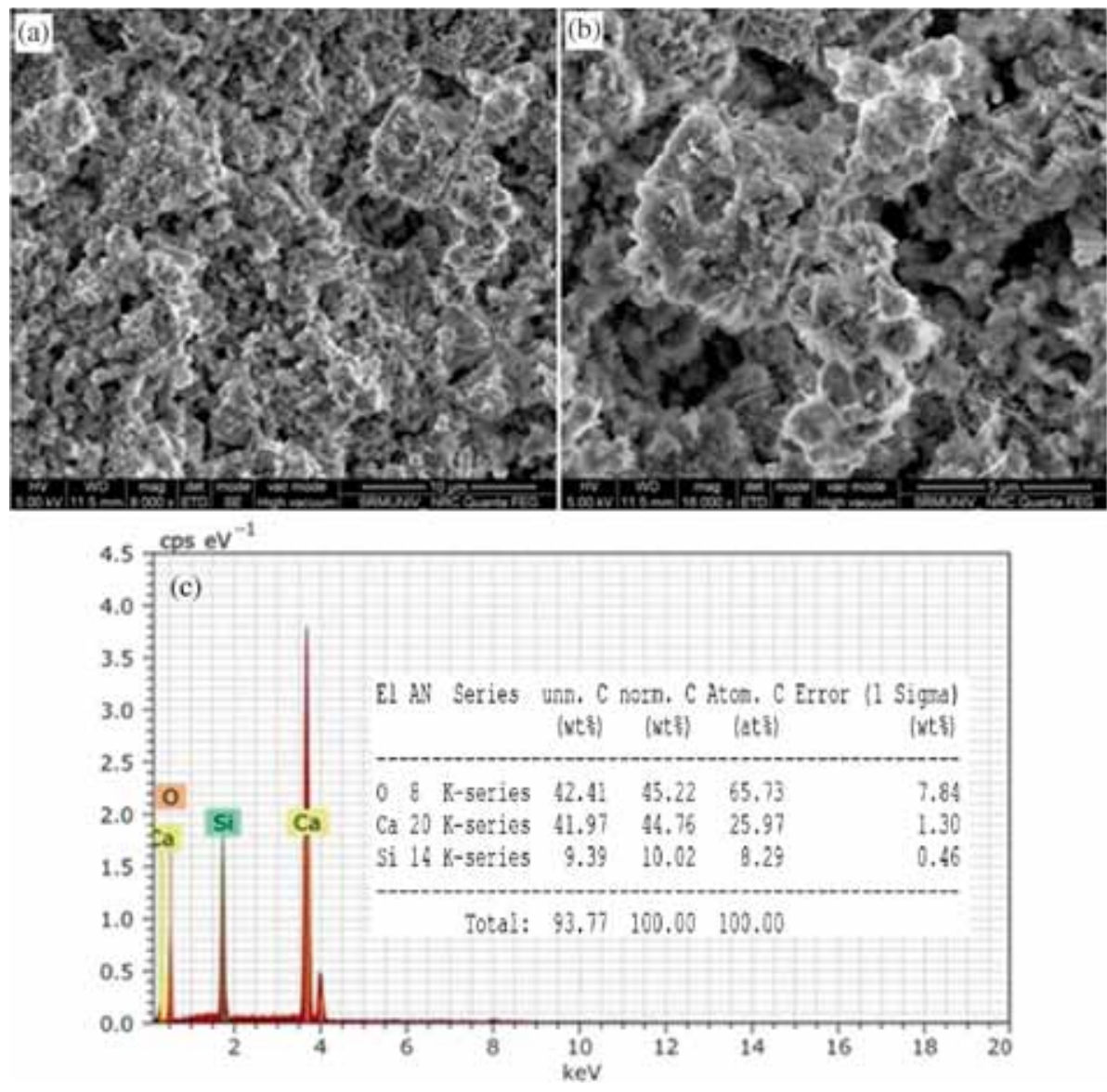

Figure 3. SEM micrographs (a, b) and EDX pattern (c) of larnite after calcination. 


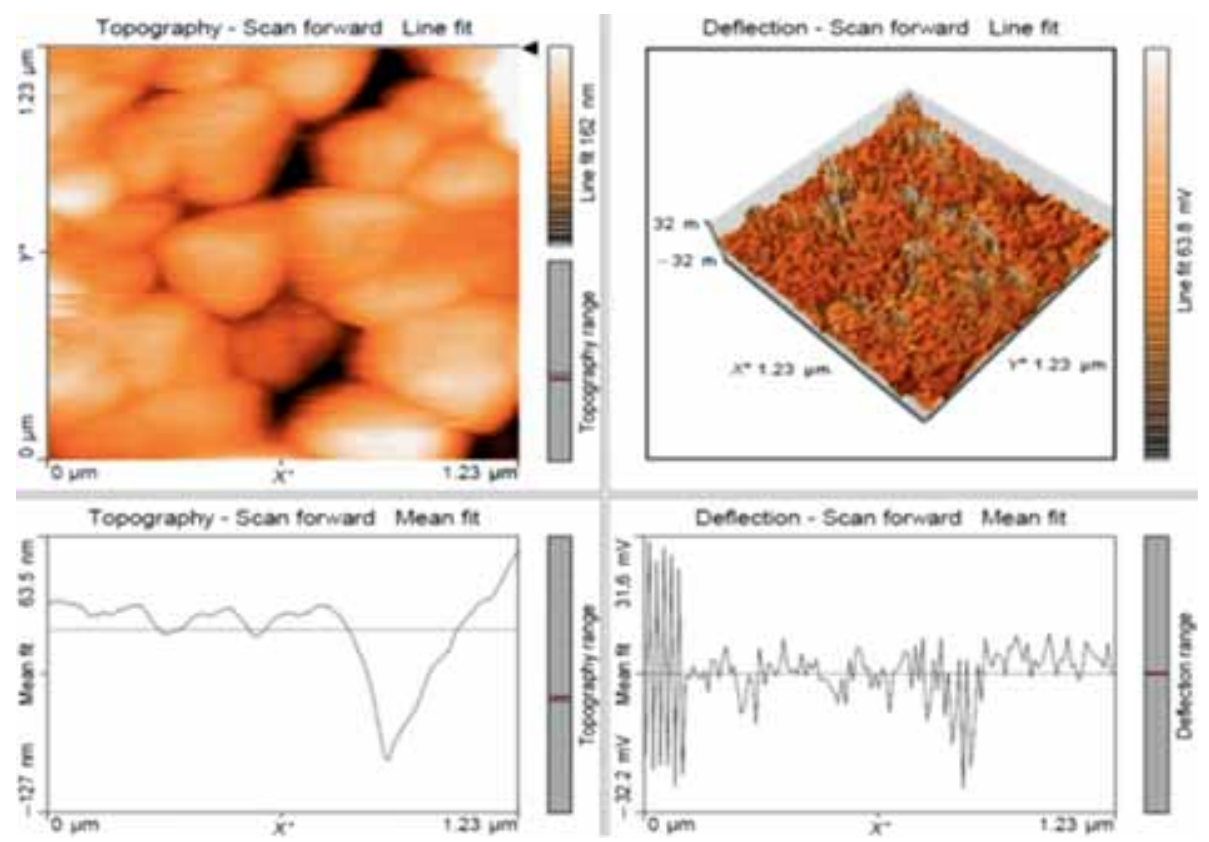

Figure 4. AFM image of larnite calcined at $800^{\circ} \mathrm{C}$ for $6 \mathrm{~h}$.

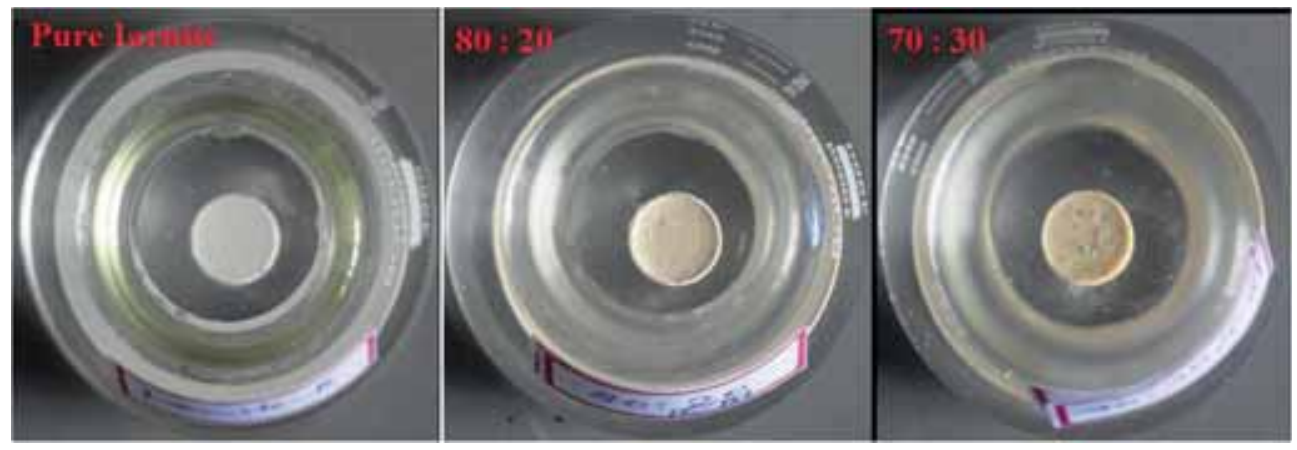

Figure 5. Scaffold images after 5 days immersion in SBF solution.

bonding with bone tissues and form bone-like apatite layer in the physiological body environment. This bonding occurs through a series of chemical and biological interactions (leaching, dissolution and precipitation) at the implant-tissue interface. Release of alkali ions $\left(\mathrm{Ca}^{2+}\right)$ from the material stimulates the apatite nucleation on the surface in the presence of silanol groups. It has been reported that ionic activity of HAP in SBF is highly influenced by the calcium ions as the calcium ion is an essential constituent of natural apatite present in mammalian bone. The newly deposited apatite layer further grows by consuming other required ions from the SBF. These interactions in body environment result in the formation of a carbonated apatite layer and create a mechanically strong chemical bond with natural bone, which is termed as 'biological fixation' [32,33]. In vitro apatite formation ability of pure larnite and larnite/chitin (80:20 and 70:30) composites was examined by immersing them in SBF for 5 days. The scaffolds were found to be stable throughout the bioactivity studies in the SBF solution as shown in figure 5 as no disintegration of the pellet was observed.

\subsection{FTIR analysis after bioactivity assay}

FTIR spectroscopy is considered to be an effective tool to study the change in surface composition during bioactivity studies. FTIR examination of larnite samples after bioactivity analysis shows close resemblance with reported literatures [11,34]. FTIR spectra (figure 6) of pure larnite and its composites with chitin after 5 days of bioactivity studies show different behaviours in SBF with respect to the intensity of different functional groups. These distinguishable variations in functional groups before and after immersion in SBF reveal the deposition of bone-like apatite on their surface. After bioactivity studies, the intense bands of $\mathrm{Si}-\mathrm{O}-\mathrm{Si}$ and $\mathrm{Si}-\mathrm{O}-\mathrm{Ca}$ are found to be completely replaced by the characteristic phosphate group, while a slight shift in $\mathrm{O}-\mathrm{Si}-\mathrm{O}$ and $\mathrm{Si}-\mathrm{O}$ peaks were noticed. After 5 days of bioactivity studies, FTIR spectra (figure 6a) of pure larnite scaffold show bending vibration of phosphate adsorption band in the range of 451-497 $\mathrm{cm}^{-1}$ and P-O's stretching vibration at $964 \mathrm{~cm}^{-1}$. Larnite/chitin composite with 80:20 ratio shows 
intense peaks of $\mathrm{P}-\mathrm{O}$ bending modes at $455 \mathrm{~cm}^{-1}$, whereas broad phosphate stretching band at $966 \mathrm{~cm}^{-1}$ (figure $6 \mathrm{~b}$ ). Larnite/chitin composite with 70:30 ratio shows bending phosphate vibrations at $459 \mathrm{~cm}^{-1}$ and stretching $\mathrm{P}-\mathrm{O}$ at $1020 \mathrm{~cm}^{-1}$. All the above mentioned bands and peaks correspond to the phosphate group present in the nucleated HAP granules on the immersed surface of the pellets. Stretching vibration of the carbonate band on the immersed surface was noted for all the three samples (figure $6 \mathrm{a}-\mathrm{c}$ ) in the range of 1420 to $1440 \mathrm{~cm}^{-1}$. This observation proves that carbonated apatite formed on the surface of samples. FTIR spectrum also reveals that with the increase in the chitin content of composite, the intensity of the phosphate also increased. Since, distorted phosphate peak was noticed for pure larnite, broadband for 80:20 ratio and sharp singlet intense peak in case of larnite/chitin 70:30 ratio were observed. Moreover, slow bioactivity was noticed for pure larnite, while rapid HAP layer formation was detected for larnite/chitin 70:30 composites. Chitin improves the bioactivity of a bioceramic when it is fabricated into composite due to its extraordinary biostimulation properties, which facilitate the HAP layer formation on the immersed surface [35].

\section{$5.2 X R D$}

XRD pattern (figure 7) of the pure larnite and its composites immersed in SBF for 5 days shows the formation of HAP on

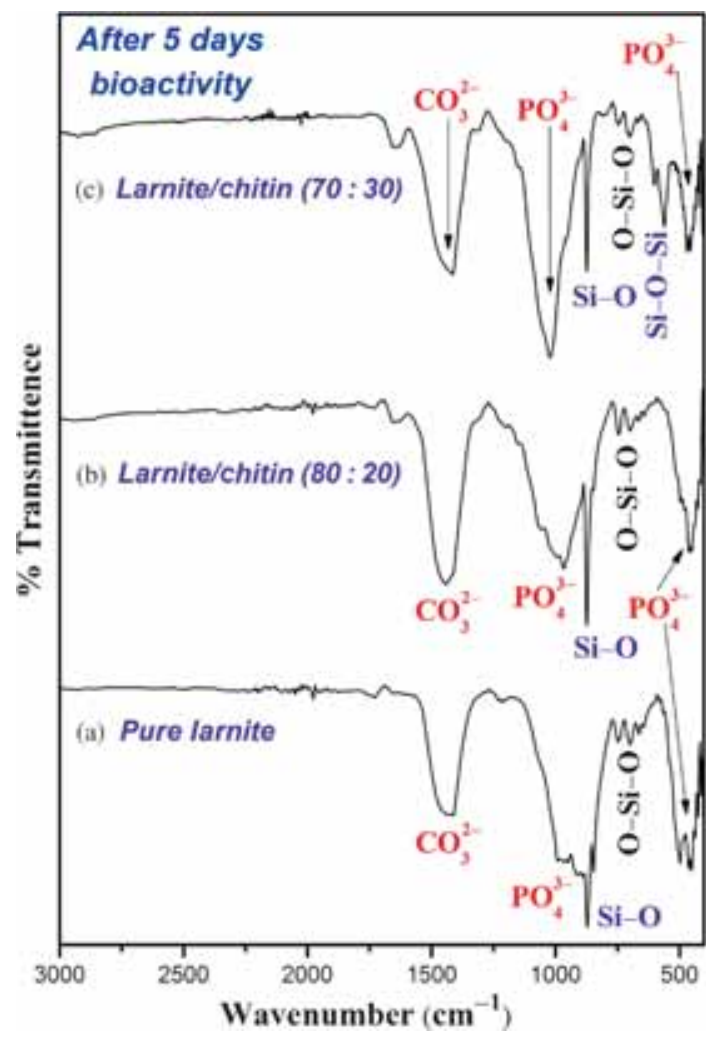

Figure 6. FTIR spectra after 5 days immersion in SBF solution: (a) pure larnite, (b) larnite/chitin composites (80:20) and (c) larnite/chitin composites (70:30). its surface. The XRD pattern of the scaffold surface shows complete disappearance of larnite peaks and appearance of HAP along with calcite phase. HAP peaks were matched with standard JCPDS data 900-2216, while calcite with 9000966. The mechanism of in vitro HAP formation is initiated by the calcite phase formation on the surface, which will be later transformed into a hydroxyapatite layer by consuming the phosphate ions present in the SBF [36].

Eggshell derived pure larnite (figure 7a) possesses slow HAP formation ability compared to the composites of larnite. Further, superior bioactivity was observed for larnite/chitin composite with $70: 30$ ratio as shown in figure 7c. It also reveals that the chitin (biopolymer) fibres incorporated into larnite (ceramic) matrix have modified the surface activity, which leads to an enhanced HAP deposition on the immersed surface.

\subsection{Surface morphology of larnite and larnite/chitin composites after bioactivity studies}

SEM images (figure 8) of pure larnite, larnite/chitin composites (80:20 and 70:30) after 5 days of bioactivity study show change in surface morphology due to the apatite deposited on all three scaffolds. The SEM images (figure 8a, b) of apatite deposited on the surface of pure larnite show uneven deposits with circular non-uniform particles embedded on the surface [9]. The observed pits and microcracks on the surface are due to the heat treatment of the pellet before SEM analysis. The XRD pattern (figure 7a) shows calcite in highly crystalline state and HAP as amorphous phase, hence, the particles

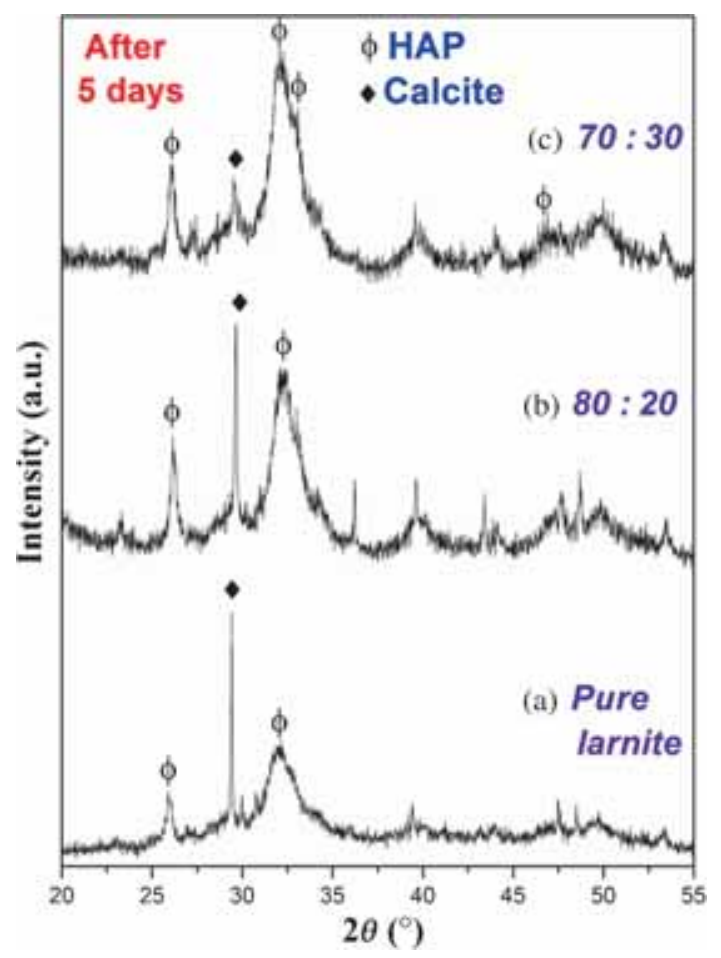

Figure 7. XRD patterns after 5 days immersion in SBF solution: (a) pure larnite, (b) larnite/chitin 80:20 and (c) larnite/chitin 70:30. 
embedded on the surface may be of calcite crystals, whereas the fine deposits may be of the deposited HAP. The larnite/chitin with 80:20 ratio reveals a cluster of accumulated calcite particles that seems to emerge from the surface (figure $8 \mathrm{c}, \mathrm{d}$ ). The average particle size was in the range of 1-3 $\mu \mathrm{m}$. The SEM micrograph of larnite/chitin with 70:30 ratio indicates that the surface was entirely covered with amorphous HAP particles having snowfall fur like morphology and a turtle shell-like microcracks (figure 8e, f). The average size of these deposited particles is noticed to be of nano regime. After bioactivity possesses, the surface of all three scaffolds cracks due to drying in hot air oven.

The HAP deposition on the material surface after immersing in SBF is due to the silanol groups formed on the surface. When silanol comes in direct contact with calcium ions from SBF, rise in positive charge on the surface is detected. This change in surface charge initiates the attraction of negatively charged phosphate ions and results in the formation of amorphous apatite. This amorphous apatite later transforms into hydroxyapatite with the increase in immersion time in SBF [37]. The nucleation of bone-like HAP will be induced on the immersed surface when the ionic concentrations of calcium and phosphate ions are relatively rich [38].

It has been previously reported that compositional modification in a material alters surface activity, which directly affects the biological response in a physiological environment (surface-activity relationship) [39]. These observations impart that HAP layer deposition is extremely influenced by the surface properties of a material and bioactivity response rapidly changes from calcite phase to hydroxyapatite phase $[40,41]$. Among all the three scaffolds, the bioactivity response in SBF was superior for larnite/chitin (70:30) ratio due to increase in polymer content in ceramic matrix, which closely resembles the composition of organic to inorganic constituent ratio in the natural bone.

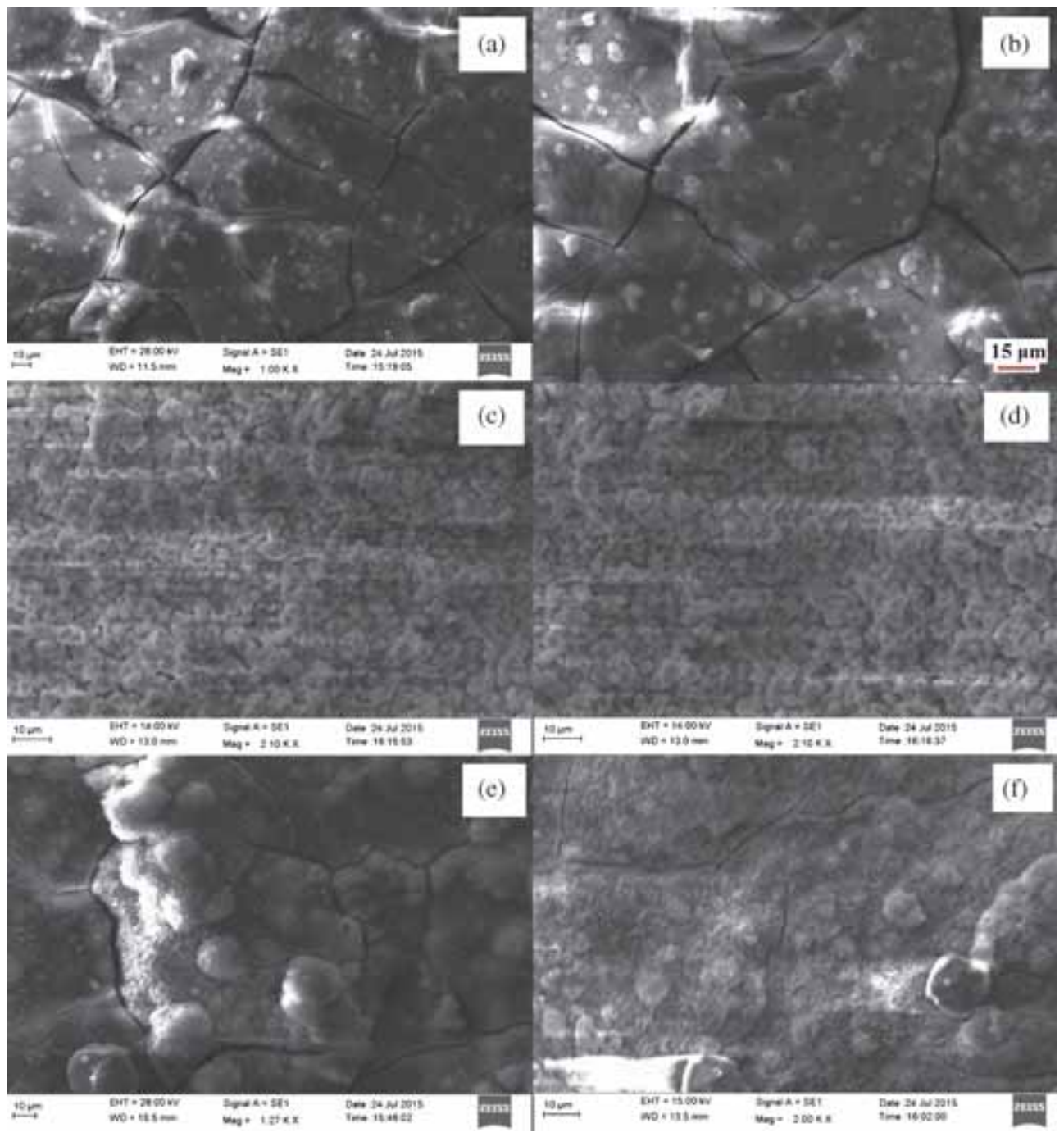

Figure 8. The surface morphology of pure larnite (a, b); larnite/chitin 80:20 (c, d); larnite/chitin $70: 30(\mathbf{e}, \mathbf{f})$ after the 5 th day immersed in SBF. 


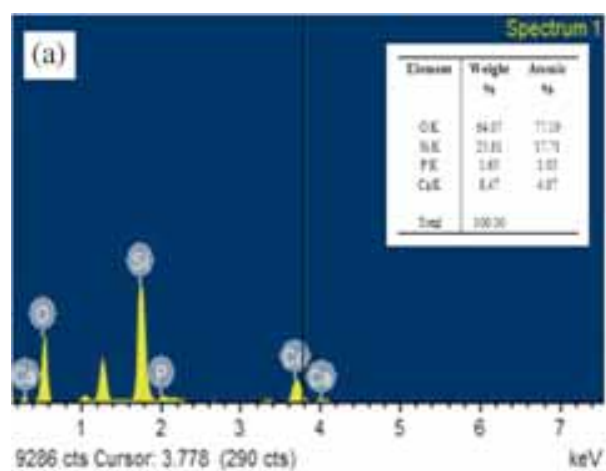

Figure 9. EDX images of larnite composites: 70:30 after 5 days bioactivity.

\subsection{Elemental analysis of composites after bioactivity}

EDX spectrum (figure 9) reveals the presence of calcium, silicon, oxygen and phosphate elements on the surface, which confirms the deposition of HAP. An EDX spectrum (figure 9a, b) shows the surface composition of larnite/chitin composite (80:20; 70:30) after bioactivity studies. The difference in intensities of elemental peaks between the composites is due to the different extent of HAP deposition. All elemental peaks are evident in larnite/chitin (70:30) composite and sharp, intense peak of phosphorus indicates remarkable HAP layer formation on the surface as compared to the less intense peaks in 80:20 composite. The disappearance of silicon peak (figure 9b) might be due to the fact that the analysed surface is completely covered by the HAP layer. In other words, it can be explained as the silanol formed during the ionic exchange between the SBF and the interface of the composite has been entirely replaced by a calcium phosphate layer on the immersed surface.

\section{Conclusion}

Single phase larnite was successfully synthesized by energy efficient sol-gel combustion method by using the raw eggshell biowaste as a calcium source and urea as a fuel. The rapid combustion rate of urea and its thermochemistry lowered the phase formation temperature of larnite. Appearance of heterogeneous agglomerated particles and pores on the surface of pure larnite was due to the release of gases during decomposition of fuel and nitrates. These surface characteristics have influenced the bioactivity response of larnite and larnite/chitin scaffolds in SBF solution. In vitro bioactivity analysis of larnite and larnite/chitin scaffolds show bone-like apatite formation on the immersed surface within 5 days. Larnite/chitin show remarkable bioactivity in SBF than pure larnite. It was also observed that alteration of chitin composition in larnite matrix has affected the apatite deposition and surface morphology of scaffolds after immersion in SBF. The surface of all the three scaffolds after bioactivity reveals a different composition of inorganic phases and morphology due to the variation in bioactivity as the composition of elements

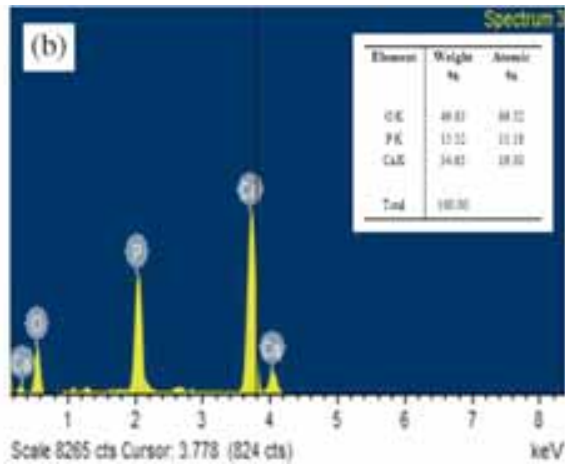

(a) larnite/chitin 80:20 and (b) larnite/chitin

on the surface is different. The particle size of deposit particles was found to vary from micrometer to nano-sized as the content of chitin was increased. Thus, increasing the polymer composition in ceramic matrix enhanced HAP layer formation ability of scaffolds. Larnite/chitin (70:30) was found to show better bioactivity among the investigated (pure larnite, 80:20 larnite/chitin and 70:30 larnite/chitin) scaffolds.

\section{Acknowledgements}

This research was financially supported by Vellore Institute of Technology Research Grants for Engineering, Management and Science (VITRGEMS). We thank DST-FIST for the XRD facility, SEM/EDX measurements and nanotechnology lab supported by NSTI, DST for AFM facility. We are also thankful to analytical services of the NRC, SRM University for FESEM characterization.

\section{References}

[1] Chevalier J and Gremillard L 2009 J. Eur. Ceram. Soc. 29 1245

[2] Hench L L and Ethridge E C 1982 Biomaterials: an interfacial approach (New York: Academic Press)

[3] Vallet-Regi M and Gonzalez-Calbet J M 2004 Prog. Solid State Chem. 321

[4] Hench L L, Splinter R J, Allen W C and Greenlee T K 1971 J. Biomed. Mater. Res. Symp. 2117

[5] Hench L L 1991 J. Am. Ceram. Soc. 741487

[6] Udduttula A and Swamiappan S 2014 Bull. Mater. Sci. 37207

[7] Wu C and Chang J 2004 Mater. Lett. 582415

[8] Wu C and Chang J 2007 J. Biomed. Mater. Res. B Appl. Biomater. 83153

[9] Gou Z and Chang J 2004 J. Eur. Ceram. Soc. 2493

[10] Gou Z, Chang J and Zhai W 2005 J. Eur. Ceram. Soc. 251507

[11] Zhong H, Wang L, Fan Y, He L, Lin K, Jiang W et al 2011 Ceram. Int. 372459

[12] Liu X, Tao S and Ding C 2002 Biomaterials 23963

[13] Cheng W, Li H and Chang J 2005 Mater. Lett. 592214 
[14] Sprio S, Tampieri A, Celotti G and Landi E 2009 J. Mech. Behav. Biomed. Mater. 2147

[15] Choudhary R, Koppala S, Srivastava A and Swamiappan S 2015 J. Sol-Gel Sci. Technol. 74631

[16] Yunos D M, Bretcanu O and Boccaccini A R 2008 J. Mater. Sci. 434433

[17] Shogren R L and Bagley E B 1999 Natural polymers as advanced materials (USA: Oxford University Press, ACS symposium series)

[18] Puppi D, Chiellini F, Piras A M and Chiellini E 2010 Prog. Polym. Sci. 35403

[19] Verma N, Kumar V and Bansal M C 2012 Pol. J. Environ. Stud. 21491

[20] Onoda H and Nakanishi H 2012 Nat. Resour. J. 371

[21] Onoda H, Nakanishi H and Takenaka A 2012 J. Ecotechnol. Res. 1685

[22] Akram M, Ahmed R, Shakir I, Ibrahim W A W and Hussain R 2014 J. Mater. Sci. 491461

[23] Kokubo T and Takadama H 2006 Biomaterials 272907

[24] Kalinkin A M, Boldyrev V V, Politovaa A A, Kalinkina E V, Makarov V N and Kalinnikov V T 2003 Glass Phys. Chem. 29410

[25] Udduttula A, Koppala S and Swamiappan S 2013 Trans. Indian Ceram. Soc. $\mathbf{7 2} 257$

[26] Klug H and Alexander L 1962 X-ray diffraction procedures (New York: John Wiley and Sons Inc).
[27] Sutka A and Mezinskis G 2012 Front. Mater. Sci. 6128

[28] Froberg L and Hupa L 2008 Appl. Surf. Sci. 2541622

[29] Paital S R and Dahotre N B 2009 Mater. Sci. Eng. R 661

[30] Saiz E, Goldman M, Gomez-Vega J M, Tomsia A P, Marshall G W and Marshall S J 2002 Biomaterials 233749

[31] Montenero A, Gnappi G, Ferrari F, Cesari M, Salvioli E, Mattogno L et al 2000 J. Mater. Sci. 352791

[32] Hench L L 1998 Biomaterials 191419

[33] Kokubo T 1998 Acta Mater. 462519

[34] Radin S R and Ducheyne P 1992 J. Mater. Sci. Mater. Med. 333

[35] Pighinelli L and Kucharska M 2013 Carbohydr. Polym. 93256

[36] Zhao Y, Ning C and Chang J 2009 J. Sol-Gel Sci. Technol. 5269

[37] Ohtsuki C, Kokubo T and Yamamuro T 1992 J. Non-Cryst. Solids 14384

[38] Hou X, Yin G, Chen X, Liao X, Yao Y and Huang Z 2011 Appl. Surf. Sci. 2573417

[39] Mohamed K R, Beherei H H and El-Rashidy Z M 2014 J. Adv. Res. 5201

[40] Kay S, Thapa A, Haberstroh K M and Webster T J 2002 Tissue Eng. 8753

[41] Palin E, Liu H N and Webster T J 2005 Nanotechnology 161828 